\title{
Malabarismos para conseguir dinero y relaciones sociales. Testimonio del sur rural de la India
}

\author{
Isabelle Guérin
}

$\mathrm{S}$ e afirma a menudo que los pobres carecen del más mínimo acumen financiero. Se da por sentado que como son pobres se hallan al margen de cualquier forma de intermediación financiera y que no cuentan con conocimientos ni habilidades en la materia. A raíz de la crisis financiera global, y en fecha más reciente de la crisis microfinanciera, se ha despertado un interés inusitado en la "educación financiera" que fortalece esta visión de los pobres como poco "sofisticados" financieramente, fruto de su inveterado analfabetismo. Empero, esta idea de la ignorancia financiera carece de sustento alguno en los estudios antropológicos. En los últimos años Collins et al. (2009) han puesto en tela de juicio el concepto mismo en su libro Portfolios of the Poor - Los valores en cartera de los pobres-. Los autores hacen un análisis pormenorizado de la forma en que los pobres manejan su flujo de efectivo para mostrar que este sector de la población dispone de habilidades y conocimientos sumamente complejos y avanzados, y que de hecho planean, calculan, se anticipan a los acontecimientos, ahorran... En ocasiones, estas estrategias y sus motivaciones nos dejan un tanto azorados, pero tienen una clara razón de ser. Una deficiencia de Portfolios of the Poor, sin embargo, radica en que Collins y sus colaboradores limitan el dinero y las finanzas a sus funciones técnicas e instrumentales. En su obra el dinero, las finanzas y el cálculo son privados de su valor moral y social. Se resta importancia a los asuntos de identidad y poder, elementos fundamentales del endeudamiento.

Un análisis socioeconómico del endeudamiento, como el que examinamos aquí, nos faculta a captar la sustancia y profundidad del fenómeno, así como la sutileza y la complejidad de los cálculos relacionados con el adeudo. Para ilustrar la complejidad de las prácticas financieras de los pobres y la sofisticación de su sistema de cálculos, hemos seleccionado el estudio de caso de una mujer rural de la India, Saraswathi. Su caso es excepcional en muchos aspectos, pero pone de manifiesto varias tendencias interesantes. Saraswathi pertenece a la comunidad de Paraiyar, una de las castas más bajas —antiguos intocables-, clasificada como casta inventariada (CI) conforme al sistema administrativo de la India.

\section{Juggling with Money and Social Relationships. A Testimony from Rural South-India}

IsABELLE GUÉRIN: Institut de Recherche pour le Développement, París, Francia isabelle.guerin@ird.fr 
Vive en una colonia - parte del pueblo reservada a la CI- en el norte de Tamil Nadu, sur de la India, a unos 80 kilómetros de Chennai, la capital del estado. Tiene 35 años y vive con su esposo y sus dos hijos. Su hijo mayor cuenta 23 años y trabaja en la compañía Nokia, en una zona industrial localizada a unos 10 kilómetros de su hogar. Su hija, de 18 años, es discapacitada y desempeña un trabajo de tiempo parcial en una organización no gubernamental (oNG). Conocemos a Saraswathi desde 2003, cuando comenzamos a entrevistarla como parte de un estudio de microfinanciamiento. Con el tiempo, quienes participamos en dicho estudio hemos forjado una estrecha relación, que nos ha permitido adentrarnos en las estratagemas de sus finanzas familiares y observar la extraordinaria diversidad de arreglos financieros en los que está involucrada, las tácticas y las estrategias que despliega para asumir sus responsabilidades, al mismo tiempo que mantiene sus relaciones y su identidad social. Uno de nosotros, Santosh Kumar, vive en Chennai y la ve con

\section{CIRCULACIÓN FINANCIERA EN LA UNIDAD DOMÉSTICA Y ENTRE LA PARENTELA}

Saraswathi se asume como la principal gestora de su unidad doméstica. Maneja todos los aspectos del presupuesto familiar y se mueve con relativa libertad, lo que dista de ser la norma dado el grado de control patriarcal en el ámbito rural del sur de la India - si bien las mujeres de la ci disfrutan de mucha más libertad que las de las castas superiores, sus movimientos y cuerpos se encuentran de todas maneras controlados- Cuenta con el total asentimiento de su esposo, lo que suele ser más la excepción que la regla: él le entrega su salario completo y no limita sus salidas ni sus entradas. Es un asunto de confianza, afirma ella. Pero considera también que el apoyo de su esposo es una compensación implícita por el comportamiento de éste. Aunque el matrimonio "arreglado" - i. e. conforme a las reglas de la endogamia- continuaba siendo normal, ellos optaron por un "matrimonio por amor" cuando ella tenía sólo 13 años, mucho más joven que el promedio, no debido a un embarazo prematuro, como sucede a menudo, sino porque se querían. Su esposo tuvo una relación extramarital poco después de su boda. Fue un duro golpe a su orgullo y no había forma de quejarse: en los matrimonios por amor los consortes son responsables de sus actos y la comunidad no asume responsabilidad alguna. Ella cree que la forma de compensarla ha sido dándole cierta libertad, incluidos los aspectos financieros.

A su vez, ha tenido que soportar la presión constante de sus parientes políticos que viven cerca. Nunca han aceptado el matrimonio por amor o al menos les sirve de pretexto para regañarla. "Toda mi vida voy a tener que mostrarles mi valía”, nos manifestó en una de nuestras primeras pláticas. Carga sobre su espalda compromisos financieros considerables de sus parientes políticos: siempre que necesitan dinero en efectivo, les ayuda a encontrar un prestamista y en ocasiones ella acepta la 
responsabilidad de la transacción. Como tiene buenas relaciones con numerosos prestamistas, esto se ha tornado rutinario. Por ejemplo, cargó con todo el financiamiento de la boda de su cuñado más joven. Nos cuenta esta historia con amargura porque siente que sus parientes políticos esperan demasiado de ella. No obstante, le gustan los desafíos, le encanta sentirse útil y no deja de expresar un cierto orgullo. "Sin mí no se las podrían arreglar y lo saben", afirma. En 2002 pidió prestadas unas 40000 rupias para la ceremonia nupcial —unos 780 dólares, que en esa época equivalían a un año y medio del ingreso anual de su unidad doméstica-. Asumió el pago de la deuda y logró hacerlo en 2006, mediante la combinación del salario de su marido y varias fuentes de actividades ilícitas que describiremos, al mismo tiempo que enfrentaba un dilema sin tregua: por una parte, admitió la responsabilidad plena de la deuda - en colaboración con su esposo, mediante el salario de éste- para salvar las apariencias frente a su familia política; por otra parte, ser capaz de reunir ciertas sumas de dinero pone en tela de juicio su moralidad, pues a menudo se sospecha que utiliza los encantos de su físico con los acreedores, y en particular su suegro siempre ha desaprobado su comportamiento.

Para pagar la deuda, además de utilizar el salario de su esposo, Saraswathi hace malabarismos con varias actividades. Solía comerciar saris que compraba en Chennai y revendía en su pueblo. Después de un tiempo dejó de hacerlo porque los comerciantes urbanos comenzaron a vender en los pueblos y se dio cuenta de que no podía competir con ellos. También manejó tandas - asociaciones de ahorro y crédito rotatorios-. En su calidad de gerente del grupo, le estaba permitido ocupar el primer turno, de modo que la cantidad que obtenía por esta vía la daba en préstamo a otras o la empleaba para saldar una deuda. Estaba autorizada asimismo a cobrar una remuneración, un porcentaje de las contribuciones de las otras socias. Tuvo que dejar esta actividad porque algunas socias se fueron sin saldar sus adeudos, además de que es probable que el surgimiento del microfinanciamiento haya contribuido a la decadencia del sistema de tandas de las mujeres. Por añadidura, compra y vende en el mercado negro artículos subsidiados de las tiendas de racionamiento, que en principio venden trigo, arroz, queroseno y azúcar a la población de bajos recursos a precios inferiores a los del mercado. Una parte significativa de los productos son revendidos en el mercado negro por varias razones: ya sea porque clientes elegibles no tienen necesidad de los productos - esto sucede, por ejemplo, con el queroseno-, porque deseen productos de mejor calidad o porque pignoraron sus cartillas de racionamiento, una práctica recurrente entre los pobres cuando están urgidos de dinero en efectivo. En fechas más recientes, Saraswathi comenzó a vender jabón, purificadores de agua, vitaminas y cosméticos de Amway, una compañía multinacional organizada conforme a un plan piramidal: los comerciantes son "distribuidores independientes" y su ingreso depende no de sus propias ventas sino de las de otros a quienes han reclutado. Saraswathi usa la red que ha construido con el tiempo gracias a su participación en la vida del pueblo y de la ong como salida.

\section{CIRCUITOS FINANCIEROS EN LA COLONIA Y MICROFINANZAS}

En la colonia muchas mujeres consideran a Saraswathi una persona de recursos puesto que ayuda con muchas cosas, en especial en lo referente a dinero en efectivo. Desarrolló este papel de liderazgo local en el curso de los años. Gracias a los innumerables trámites que ha debido hacer en diferentes instancias para conseguir certificados, becas y otros beneficios a favor de su hija discapacitada, ha acumulado una gran experiencia en lidiar con la burocracia de los servicios públicos. Aparte, durante casi diez años, se involucró activamente como líder de un grupo de "autoayuda" - Self Help Groups, sHG-, la forma dominante de microfinanzas en Tamil Nadu. Los SHG normalmente reúnen entre 12 y 20 
mujeres del mismo barrio que primero circulan dinero entre ellas y después se vuelven elegibles para préstamos externos. Éstos son otorgados por un banco con el respaldo de una ong local, que supuestamente desempeña el papel de facilitador. A petición de la directora de la ONG, es además voluntaria en varias actividades emprendidas por ésta: reuniones, eventos públicos, entrenamiento, etcétera.

Saraswathi es considerada una suerte de "reserva de efectivo", principalmente para las mujeres de la CI de su barrio, en ocasiones también para mujeres de la CI de pueblos vecinos a quienes conoció a través de la red de la ONG. Con menos frecuencia presta dinero a hombres, lo que es contrario a las normas, pero sucede. Los montos suelen ser reducidos — de 100 a 500 nuevas rupias indias (NRI) - y para casos de emergencia. A veces, la cantidad se eleva a 15000 o 20000 NRI - casi un tercio del ingreso familiar anual antes de que su esposo tuviera una plaza permanente y su hijo comenzase a trabajar-. Funge como aval o intermediaria, se presta a sí misma después de haber pedido prestado a alguien más. Las mujeres la necesitan y la aprecian porque carecen de contactos con los prestamistas, de capacidad de moverse - muchos prestamistas operan en la ciudado por una cuestión de discreción: no quieren que sus maridos se enteren de sus transacciones financieras. Confiesa que no cobra por este tipo de ayuda, pero recibe beneficios indirectos, como mejorar su situación crediticia entre los prestamistas locales y lograr mejores condiciones de crédito. El hecho mismo de que actúe de intermediaria de otras mujeres prestatarias la autoriza a tomar más dinero prestado a menor costo. Cuando pide prestado a nombre de alguien más, a menudo guarda una parte para ella, pide a la prestataria a quien sirve de aval que pague los primeros plazos y ella se encarga de los últimos pagos. Este sistema le permite disponer de un plazo más largo para hacer su reembolso. El "respeto" y la "gratitud" de las mujeres locales es otro beneficio indirecto: es una cuestión de "posición social", puesto que es muy respetada en el ámbito local. La "gratitud" de las mujeres significa asimismo que están disponibles en caso de necesidad. Saraswathi admite, con una encantadora sonrisa, que puede "controlarlas", lo que quiere decir que es capaz de movilizarlas para reforzar las redes de patronazgo en las que participa activamente. Numerosas ONG usan un sistema de patronazgo y exigen a sus "beneficiarias" asistir a muchos actos, en los que descansa su legitimidad. Éstos incluyen visitas al pueblo - las mujeres deben estar presentes y disponibles en cualquier momento-, de los donantes - su pueblo es una suerte de escaparate, las mujeres atestiguan ante los donantes los múltiples beneficios que reciben de la organización - y eventos, como el del Día Mundial de la Mujer, planeados por la ong o por sus aliados, en particular los partidos políticos. Las alianzas de las ONG con los partidos políticos son inevitables para ser elegibles para los planes gubernamentales. Movilizar mujeres supone, además, convencerlas de aceptar nuevos planes a los que se muestran reacias. Por ejemplo: un plan de microseguros cuyos beneficios las mujeres apenas entienden. Saraswathi recurre a su vez a su red de mujeres para mantener relación con las castas superiores a las que pide dinero prestado de manera regular, que retribuye con ayuda y mano de obra. Por último, mantiene una estrecha relación con las autoridades locales: con frecuencia acarrea a las mujeres a actividades públicas -mítines políticos o reuniones municipales- para las que siempre es difícil hallar gente lista para participar. A cambio goza de un acceso privilegiado a recursos de varios tipos y logra una entrada más fácil a los servicios administrativos, tanto para ella como para su red. De hecho, en 2008 presenciamos cómo ayudaba a unas vecinas a abordar al recaudador del distrito por un asunto relacionado con un título de propiedad.

Fungir como "reserva de efectivo" le permite a Saraswathi tener en su poder los préstamos grupales, hecho que nadie le cuestiona. Es el caso del primer préstamo externo que obtuvo el grupo en 2008, que se repartió oficialmente entre cinco mujeres, pero en realidad ella usó a título personal tres quintas partes. Además, controla por entero no sólo sus propios 
préstamos, sino los de su hija y sus cuñadas. Se trata de "arreglos internos", como les llama ella a los múltiples servicios que les proporciona. Para su casa tomó prestadas 70000 NRI en 2010 - una cantidad muy por encima de la suma para la que es elegible- - y en otras circunstancias emplea los préstamos principalmente para "circular el dinero" - pagar deudas-.

\section{CIRCUITOS FINANCIEROS FUERA DE LA COLONIA}

En 2009 su esposo obtuvo un contrato permanente en la estación del ferrocarril y un año más tarde su hijo comenzó a trabajar en Nokia. Estos dos hechos han reforzado de manera considerable el poder crediticio de la unidad doméstica y han contribuido a crear nuevas necesidades sociales. Un contrato permanente brinda una posición social específica que pocos miembros de las CI disfrutan, siempre y cuando los niveles de vida encajen en ello: construir una nueva casa es un primer paso. Saraswathi tomó la iniciativa de renovar su casa y lo ha hecho gradualmente. Mientras muchas casas del pueblo tienen techo de paja y muros de adobe, la de ella ya era de concreto y la mejoró: primero añadió cuartos y después colocó piso firme. En diciembre de 2010 ya había pedido prestadas 400000 NRI y planeaba solicitar 200000 más para terminar la casa y organizar una fiesta para celebrar el acontecimiento. Consiguió el préstamo de 400000 rupias de varias fuentes: pignoró las joyas de su hermano - unas 30000 rupias-, pidió prestadas 70000 a su grupo de garantía solidaria (GGs), otras 50000 a su amante, 45000 a su tío, 100000 a dos bancos - 50000 cada uno- gracias a una amiga que le sirvió de aval y unas 70000 más a dos personas de castas superiores. En un medio en el que los bancos discriminan abiertamente a los miembros de las cr y en el que las castas superiores todavía ejercen algún control sobre las inferiores por medio de las deudas, una y otra práctica continúan siendo regulares. Su esposo también obtuvo 30000 rupias de préstamo de su empresa. Al mismo tiempo, ella comenzó una tanda. La aportación mensual era de 1500 rupias y la suma total será de casi 100000 . Tiene pensado usar ese dinero para seguir con la renovación de su casa. En relación con el ingreso de la unidad doméstica - en este momento de unas 8000 NRI mensuales- el servicio de la deuda es muy pesado, pero se las arregla con base en la multiplicidad de plazos de cada prestamista. Tres prestamistas exigen pagos mensuales estrictos: el fondo de la tanda, la empresa donde trabaja su esposo y los bancos; otros establecen sólo el pago de los intereses y el capital puede ser saldado al final -el dueño de la casa de empeños, las personas de las castas superiores-, mientras que otros más no piden intereses pero pueden demandar el pago de la deuda en cualquier momento en caso de necesidad - hermano, tío-.

Como se indicó, la relación que mantiene con las dos personas de las castas superiores es característica de las relaciones patrón-cliente. Cubre normalmente los intereses $-2 \%$ mensual - y en ocasiones parte del capital, lo que la autoriza moralmente a pedir prestado de nuevo. No obstante, el dinero es sólo un aspecto del costo. Tiene que brindar múltiples servicios, como la compra de alimentos en la tienda de racionamiento - muchas personas de las castas superiores quieren aprovechar los productos subsidiados sin tener que acudir a esas tiendas - o tareas domésticas, en particular cuando hay alguna ceremonia, ya sea boda o funeral. Poder acarrear mujeres como mano de obra es un aspecto crucial en estas circunstancias. Su esposo, como electricista, es requerido con frecuencia para dar mantenimiento a aparatos eléctricos, desde televisores hasta bombas de motor. Estar disponible a cualquier hora para brindar servicios gratis y mostrar "gratitud" y "respeto" forma parte del acuerdo tácito con sus acreedores.

A semejanza de lo ocurrido en la boda de su cuñado, logra reembolsar la deuda combinando los salarios de su esposo e hijo, sus propias fuentes de ingreso y pequeñas sumas de dinero que obtiene aquí y allá pignorando sus joyas o las de sus vecinas, su tía o su cuñada. La circulación de joyas, que funcionan casi como dinero en efectivo, es sumamente dinámica. 
También pide prestado a mujeres locales de las castas superiores, a la directora de la ONG y a prestamistas ambulantes, pero esta opción es el último recurso debido al costo: hasta $10 \%$ mensual, mientras que otros prestamistas no suelen cobrar más de $3 \%$. Ser miembro de una tanda le permite pedirle a la presidenta hasta 5000 NRI durante periodos breves. Cuando no puede cumplir con los reembolsos, decide a quién pagar primero según consideraciones de índole económica y financiera. Trata de cubrir en primer término las deudas más caras, pero se siente obligada a mantener su buen crédito y su "posición social". En lo tocante a las deudas contraídas para concluir su casa, su prioridad es el préstamo de su esposo con su empresa. Él goza de un buen puesto y no puede darse el lujo de incurrir en críticas. Siguen los préstamos personales que consiguió de la directora de la ONG. "No quiero verme rebajada frente a las mujeres de mi red social", afirma, y trata asimismo de disimular estas deudas. No desea ser acusada de estar motivada únicamente por el dinero en su compromiso con la ONG, como me dijo en una ocasión. Durante una de nuestras últimas visitas, señaló que una de sus prioridades era el pago de deudas. En ese momento se refería específicamente al débito con su cuñada - la hermana de su marido-, que la acusó de haber progresado en la vida gracias a su esposo, lo que la hizo sentirse humillada e irritada. Por lo pronto intenta limitar la dependencia lo más posible. Sostiene que teme mucho más las críticas de su círculo cercano y que no le importan los prestamistas privados, aunque a menudo son muy agresivos y sus tasas de interés exorbitantes. Tampoco le molesta tener que estar lista para sus "patronas". Su prioridad es mantener su posición social y su rango en su propia familia y en su comunidad.

\section{DISCUSIóN}

La posición de Saraswathi es excepcional en muchos aspectos. No sólo su esposo goza de una buena posición laboral sino que, además, es sumamente ayudador. Su dinamismo y sus habilidades sociales - la buena mano que tiene con la gente- probablemente sean poco comunes. Aun si el caso de Saraswathi no es la regla, la manera en que hace malabarismos con el dinero y los vínculos sociales que cultiva reflejan varias tendencias amplias. Primero, el caso de Saraswathi pone al descubierto lo complejo que puede ser el sistema del presupuesto familiar: ella no tiene acceso directo a la banca financiera y es prácticamente analfabeta, pero esto no le impide calcular sus operaciones financieras con gran meticulosidad. Suele pensarse que el cálculo es el coto de la esfera económica y de la teoría económica. Se cree que el cálculo sólo busca satisfacer el interés personal sobre la base de indicadores cuantificables y unidades de medida. Sin embargo, la historia y la etnografía muestran que el cálculo va más allá de los actos económicos. Sus razonamientos y su razón de ser son complejos y están arraigados en contextos sociales (Weber, 2000). Los pobres no son sólo estómagos desesperados por sobrevivir. Tratan de progresar o mantener identidades individuales y grupales particulares. Forman parte de una gama de redes de derechos y obligaciones que pueden tratar de reforzar, conciliar o huir. Los cálculos sirven a múltiples fines, a veces contradictorios. Como se observa en el caso de Saraswathi, éstos pueden incluir cómo sobrevivir, respetar las estructuras sociales, posicionarse en las redes sociales y jerarquías locales, o afirmar o tratar de afirmar la individualidad propia.

Los vínculos financieros son fundamentales en estos procesos debido a su significado social (Servet, 2006; Guérin, Morvant-Roux y Servet, 2011; Morvant-Roux, 2009). Las deudas constituyen ante todo vínculos sociales entre individuos, transmiten sentimientos y emociones como la dignidad, el prestigio, la respetabilidad o, por el contrario, la vergüenza o la humillación. Se encuentran enraizadas en responsabilidades y obligaciones más amplias (Shipton, 2007). Como sostiene Magdalena Villarreal, prestatarios y prestamistas echan mano de marcos específicos de cálculo, definidos como conjuntos de 
herramientas conceptuales que están disponibles y son movilizados por los individuos en situaciones específicas para sopesar riesgos, tomar decisiones financieras y escoger entre varias herramientas financieras (Villarreal, 2009). Los marcos de cálculo tienen componentes socioculturales, legales y normativos. Las herramientas de cálculo no son necesariamente complejas o formales, pero sí tienen múltiples dimensiones cognitivas, rutinarias y de raigambre social (Coquery, Menant y Weber, 2006). Surgen de la interacción social y de este modo están enraizadas en las posiciones sociales de los individuos. Aquí hemos observado que el género, la casta y la clase son elementos coadyutorios en la conformación de las decisiones y las determinaciones de Saraswathi.

Aunque su esposo goza de una buena posición, debido a su situación de casta ni ella ni él son elegibles para obtener préstamos bancarios, para lo cual necesitan un intermediario. Lejos de ser la excepción, la discriminación de los miembros de la CI es un hecho de sobra conocido (Chavan, 2007). Gracias a la migración y a los movimientos sociales de las castas inferiores, están en vías de desaparición las relaciones patrón-cliente basadas en el control de la tierra. En la región donde vive Saraswathi, las cI disfrutan de una posición mucho mejor que en otras partes del estado. En esa zona los pobladores han podido organizarse políticamente, muchos hombres trabajan en Chennai y su área circunvecina y pueden evadir en parte la dependencia de las castas superiores en el ámbito local. No obstante, persiste la jerarquía social y la categoría acreedordeudor es una de las formas por medio de las cuales se preserva.

La manera en que Saraswathi trata las responsabilidades financieras en la unidad doméstica y con su parentela ejemplifica a qué grado las transacciones financieras son inseparables de consideraciones de índole emocional y afectiva. Como sostiene Viviana Zelizer (2005), cuando la esfera económica se topa con la privada no se intercambian sólo dinero, bienes o servicios, sino también sentimientos, emociones y posición social. Todos los miembros de una unidad doméstica están involucrados en un proceso continuo e intensivo de negociación de sus respectivas relaciones y posiciones, y las transacciones financieras desempeñan aquí un papel clave. Aun si las responsabilidades financieras que Saraswathi mantiene con su parentela posiblemente son excepcionales, la manera en que las usa para negociar su posición es característica de las imbricaciones entre las transacciones financieras y el posicionamiento social de los miembros de la familia: cualquier transacción financiera es una oportunidad de organizar y reorganizar la naturaleza y el significado de las relaciones familiares, así como el lugar y la posición de todos los que se hallan implicados.

Las tácticas y las estrategias de Saraswathi también plantean cuestiones acerca de las ambigüedades de las responsabilidades financieras de las mujeres. En muchas circunstancias - el sur rural de la India no es la excepción- las mujeres tienen la obligación de asegurar el equilibrio del presupuesto familiar con acceso no sólo a recursos limitados sino también a veces mal controlados (Dwyer et al., 1988). Numerosas mujeres se ven forzadas a la dependencia financiera y son enteramente responsables del manejo del presupuesto de la unidad doméstica, sin otra opción más que adoptar múltiples estrategias de ahorro, solicitud y entrega de préstamos y crear sus propios circuitos financieros (Guérin, 2011), al tiempo que deben seleccionar con suma cautela a su acreedor para evitar cualquier sospecha acerca de su moralidad. Saraswathi es afortunada a este respecto, en el sentido de que su esposo le entrega su salario completo, pero no escapa al riesgo de verse acusada de ser una mujer ligera de cascos. Él se muestra favorablemente dispuesto, pero las críticas provienen de sus parientes políticos y ahora de su propio hijo. La mayoría de las mujeres enfrenta estos preceptos contradictorios, si bien en diferentes grados. El acceso al endeudamiento se halla muy determinado por el género (Johnson, 2004) y esto tiene que ver con el control del cuerpo y la sexualidad de las mujeres. 
El papel de Saraswathi en su grupo de autoayuda y en la ONG refleja asimismo una realidad más amplia. Mientras los micropréstamos son presentados por sus promotores como una forma de iniciar microempresas y erradicar el endeudamiento informal, en la práctica su principal efecto es ayudar a las mujeres $-\mathrm{O}$ a sus esposos y parientes políticos- $\mathrm{a}$ tener un mejor manejo de sus flujos de efectivo: los microcréditos son utilizados sobre todo para costear el consumo o saldar deudas anteriores. El surgimiento o fortalecimiento de las mujeres intermediarias que usan a su grupo para posicionarse dentro de redes locales de vínculos patrón-cliente es otro efecto indeseado y Saraswathi es un buen ejemplo de ese fenómeno.

Hemos dado seguimiento a la implementación y evolución del movimiento de los grupos de autoayuda en diferentes partes de Tamil Nadu durante los últimos nueve años y nuestro diagnóstico es similar en todos los lugares donde hemos trabajado: el efecto más visible de éstos es el surgimiento de una o ya desempeñaban un papel de liderazgo local. Entre tanto, los grupos de ayuda solidaria ofrecen nuevas oportunidades a otras. En todos los casos, el control - relativo- que ejercen sobre los flujos monetarios y los miembros de grupos de ahorro y crédito y los servicios múltiples que ofrecen las faculta a participar en circuitos locales de distribución de riqueza. La llegada de empresas multinacionales como Amway, que descansan en "distribuidores independientes", refuerza incluso los circuitos femeninos previos.

El sistema administrativo de Saraswathi pone de manifiesto la frecuencia y complejidad de las prácticas de "hacer malabarismos" (Roesch y Heliès, 2007; Wampfler, Bouquet y Ralison, 2013), que implica literalmente lanzar, agarrar y mantener varias cosas en el aire al mismo tiempo, lo que exige rapidez y destreza, pero también riesgos. Estas tres facetas son excelentes para evocar la naturaleza de las prácticas financieras en las circunstancias actuales: como muchas otras, Saraswathi combina múltiples

herramientas financieras para pedir prestado, reembolsar el préstamo y volver a pedir prestado - se pide prestado a una instancia para reembolsar a otra- Cambia de rol entre deudor y acreedor, y aquí nos topamos con una práctica recurrente aun entre mujeres mucho más pobres que Saraswathi (Morvant-Roux, 2009).

Sin duda, hacer malabarismos con las deudas es una forma de cálculo financiero por medio de la cual se trata de sustituir deudas caras por otras más baratas. Es también una cuestión de temporalidad, dado que los acreedores imponen diferentes plazos de reembolso. Pero, como hemos visto, las motivaciones sociales también cuentan. Las prácticas malabares a menudo reflejan selecciones deliberadas, estrategias o tácticas destinadas a multiplicar y diversificar las relaciones sociales y fortalecer o debilitar el peso de los lazos de dependencia. Hemos observado que las lógicas múltiples de endeudamiento entran en tensión constante, con razonamientos sutiles y complejos y sistemas de compensaciones. Esto redunda en una plétora de prácticas financieras complementarias y a menudo inconmensurables e insustituibles.

\section{A MANERA DE CONCLUSIÓN: LA FALACIA DE LA “EDUCACIÓN FINANCIERA"}

La educación financiera no es una idea nueva. Los proyectos caritativos han buscado inveteradamente auxiliar a los pobres a manejar mejor sus presupuestos. Ahora bien, en la última década, la educación financiera se ha convertido en el grito de guerra tanto en los países desarrollados como en los que están en vías de desarrollo. Un informe de la Organización para la Cooperación y el Desarrollo Económicos (ocDE), considerado documento de referencia, declara que en un mundo crecientemente financializado, en el que los individuos se ven obligados a usar herramientas financieras cada vez más complejas, la educación financiera ayudaría a los individuos a 
sacar provecho de las mejores oportunidades del mercado (oCDE, 2005). La educación financiera es un asunto de información y habilidades, como entender las tasas de interés, aprender a elaborar un presupuesto y comparar ofrecimientos de préstamos. Es asimismo una cuestión de comportamiento apropiado, como el ejercicio de la prudencia, la planeación y la moderación en el endeudamiento.

Los programas de alfabetización financiera amplios surgieron por vez primera a fines de los años noventa del siglo pasado en los países más "financializados", como Estados Unidos, Gran Bretaña y Australia. Acto seguido, fueron entendidos y adoptados por la mayoría de los países del norte (Erturk et al., 2007). La fiebre de la educación financiera parece ahora haberse extendido por todo el globo. Según la reseña de la oCDE, 75 países están actualmente involucrados en programas de educación financiera pública y privada (OCDE, 2005). Brasil, Rusia, India, China y Sudáfrica (los BRICs) y otros países emergentes, enfrentados al endeudamiento creciente de las unidades domésticas y al rápido desarrollo de los mercados financieros, han favorecido en particular ese tipo de programas.

En países con niveles bajos de la así llamada inclusión financiera "formal", pero donde se está expandiendo el microfinanciamiento, los participantes en financiamientos por medio de microcréditos con frecuencia crean programas de educación financiera. Como secuela de la reciente crisis microcrediticia con visos delincuenciales, se espera que la incorporación de educación financiera a los servicios financieros proteja a los consumidores y mitigue los riesgos de quiebra de las instituciones de financiamiento microcrediticio (IFM) (CGAP, 2011). Las ONG y las organizaciones de ayuda bilateral y multilateral son coadyutorias aquí. Por ejemplo, en África oriental y occidental, el Department for International Development (DFID) puso en operación un Fondo de Educación Financiera para proyectos educativos con el fin de que los ciudadanos africanos aumenten su "capacidad financiera", la cual es definida como una combinación de "conocimientos, habilidades, actitudes y comportamientos". El Banco Mundial ha seguido sus pasos y aprobó en fecha reciente un fideicomiso de 15 millones de dólares etiquetado para alfabetización financiera. En estas iniciativas los grupos corporativos también desempeñan cierto papel, por ejemplo, los bancos o fundaciones bancarias, como Citigroup o Visa. El programa globalmente más ambicioso, cuyo lema "De la pobreza a la prosperidad" promete mucho, posiblemente sea el Programa de Educación Financiera Global, creado por dos organizaciones con sede en Estados Unidos, Oportunidades Microfinancieras y Libertad y Hambre, y funciona ya en 46 países.

Si bien la educación financiera ha sido recibida con cierto entusiasmo, también le han llovido fuertes críticas. Éstas tienen que ver ante todo con asuntos regulatorios, porque la educación financiera es considerada por lo común como un sustituto de la regulación comercial (Dickerson, 1999; Ertuk et al., 2007), como manifiestan abiertamente muchos de sus promotores. ${ }^{1}$ Según Erturk et al. (2007), la conseja popular dicta que la inclusión financiera puede redundar en beneficios privados y sociales, mientras los ciudadanos puedan lograr un creciente alfabetismo financiero. Una crítica adicional ha sido que se soslayan los factores estructurales del sobreendeudamiento, lo que una vez más transfiere la responsabilidad de las instituciones al individuo. Muchos promotores de la educación financiera asumen implícitamente que la mayoría de los deudores

\footnotetext{
${ }^{1}$ Durante un discurso oficial en 2005, Alan Greenspan, entonces presidente del Banco Mundial, reconoció los beneficios de la desregulación financiera en la expansión de oportunidades de crédito para los pobres, al tiempo que destacaba la necesidad actual de educación financiera (Erturk et al., 2007). Un informe de la OCDE acerca de la educación financiera admite explícitamente que beneficiaba a los reguladores, "a medida que consumidores financieramente alfabetos pueden allanar el camino para facilitar la actividad supervisora y permitir niveles más bajos de intervención regulatoria" (OCDE, 2005: 13). En un informe más reciente, se dice que la educación financiera no es un sustituto de la regulación del mercado, pero que "un manejo financiero sano por parte de las unidades domésticas contribuye al crecimiento económico" (BIRD-BM, 2009: 8).
} 
son irresponsables o ignorantes de las reglas del juego crediticio. ${ }^{2}$ Ahora bien, cuando la gente contrae deudas y se sobreendeuda, ya sea porque está crónicamente corta de fondos o por una catástrofe imprevista, necesita algo más que clases de alfabetismo o asesoría crediticia. En numerosos casos, el principal escollo para la salud financiera a largo plazo es un ingreso insuficiente e irregular y no los malos manejos financieros (Porter y Thorne, 2006). En estas circunstancias, el crédito formal o informal y los servicios de ahorro sustituyen a los sistemas de protección social faltantes. Sería así poco realista que la única solución proviniera de un alfabetismo financiero mejorado.

Un tercer problema estriba en la ignorancia de los marcos locales de cálculo y administración (Villarreal, 2004 y 2009). El grueso de los escritos acerca del alfabetismo financiero asume que los individuos cometen errores constantes de manejo financiero e incurren en comportamientos "subóptimos". La mayoría de los programas de educación financiera tratan de fomentar un entorno colaborador y aceptante, por ejemplo, con énfasis en la necesidad de cursos de acción que toman en cuenta las especificidades locales, pero el lenguaje de los libros de texto refleja una profunda ignorancia de la manera en que la gente percibe y usa las finanzas. Otro supuesto erróneo muy extendido es que los grupos marginados, como las mujeres, las minorías étnicas, los inmigrantes y la gente con escasa educación formal, son a menudo los grupos financieramente más analfabetas (Martin, 2007). Los "errores" frecuentes y los comportamientos "subóptimos" citados en la literatura y en los módulos docentes incluyen la falta de ahorro, de planeación y presupuestación, el uso

\footnotetext{
${ }^{2}$ Por ejemplo, en el sitio de la Puerta Internacional para la Educación Financiera (PIEF) se afirma que el interés en la educación financiera proviene de la observación de que los individuos asumen más riesgos mientras su conocimiento financiero es extremadamente bajo. Esto se traduce en un "comportamiento pasivo flexible", que a su vez deriva en numerosos problemas, comenzando con "excesiva deuda familiar". La crisis de las tasas subprime se cita entrecomillada (http://financial.org/pages/=,3417,en _39665975_39667032_1_1_1_1_1,00.html).
}

excesivo de la deuda y la ignorancia de conceptos financieros básicos, como las tasas de interés, el funcionamiento del interés compuesto, la diferencia entre valores reales y nominales, y los elementos básicos de la diversificación del riesgo.

El testimonio de Saraswathi resalta la existencia de know-how y habilidades extremadamente complejas y sofisticadas, y muestra que los pobres piden prestado y ahorran, pero también planean, calculan y anticipan. Las estrategias y motivaciones implicadas en todo este proceso pueden a veces llenarnos de asombro, aunque tienen su propia razón de ser. Ya sea con el fin de manejar los gastos cotidianos, vérselas con emergencias o reunir sumas elevadas de dinero, las unidades domésticas de bajos recursos usan y combinan una enorme variedad de herramientas financieras y además, de forma por demás regular, inventan nuevas. Dista de ser cierto que un ingreso pobre equivale a una pobre intermediación financiera, y el alto nivel de fondos prestados, reembolsados, recuperados, depositados y retirados, así como la frecuencia de las transacciones, puede ser impresionante. Luchar por que el dinero les alcance no impide a los pobres ahorrar, acumular y calcular.

\section{BIBLIOGRAFÍA}

Banco Internacional de Reconstrucción y Desarrollo-Banco Mundial (BIRD-BM), 2009, The Case for Financial Literacy in Development Countries. Promoting Access to Finance by Empowering Consumers, Organización para la Cooperación y el Desarrollo Económicos, Banco Mundial, Department for International Development, Consultative Group to Assist the Poor, Washington.

Chavan, Pavalli, 2007, "Access to Bank Credit Implications for Dalit Rural Households", en Economic and Political Weekly, 4 de agosto, pp. 3219-3224.

Collins, Daryl et al., 2009, Portfolios of the Poor. How the World's Poor Live on \$2 a Day, Princeton University Press, Princeton.

Consultative Group to Assist the Poor (CGAP), 2011, Credit Reporting at the Base of the Pyramid. Key Issues and Success Factors, Access to Finance Forum, núm. 1, en 
línea: <http://www.cgap.org/sites/default/files/CGAPForum-Credit-Reporting-at-the-Base-of-the-Pyramid-Oct-2011.pdf $>$.

Coquery, Natacha, François Menant y Florence Weber (eds.), 2006, Écrire, compter, mesurer. Vers une histoire des rationalités pratiques, Éditions rue d'Ulm, París.

Dickerson, Mechele, 1999, "Can Shame, Guilt, or Stigma be Taught? Why Credit-focused Debtor Education May Not Work", en Loyola of Los Angeles Law Review, vol. 32, núm. 4, pp. 945-964.

Dwyer, Daisy Hilse et al. (eds.), 1988, A Home Divided: Women and Income in the Third World, Stanford University Press, Stanford.

Erturk, Ismail et al., 2007, "The Democratization of Finance? Promises, Outcomes, Conditions", en Review of International Political Economy, vol. 14, núm. 4, pp. 553-575.

Guérin, Isabelle, 2011, "Do Women Need Specific Microfinance Services?”, en Beatriz Armendáriz y Mark Labie (eds.), Handbook of Microfinance, World Scientific Publishing, Londres, Singapur, pp. 563-589.

, Solène Morvant-Roux y Jean-Michel Servet, 2011, "Understanding the Diversity and Complexity of Demand for Microfinance Services: Lessons from Informal Finance", en Beatriz Armendáriz y Mark Labie (eds.), Handbook of Microfinance, World Scientific Publishing, Londres, Singapur, pp. 563-589.

Johnson, Susan, 2004, "Gender Norms and Financial Markets: Evidence from Kenya”, en World Development, vol. 32, núm. 8, pp. 1355-1374.

Martin, Matthew, 2007, "A Literature Review on the Effectiveness of Financial Education", en Federal Reserve Bank of Richmond, Working Paper Series, núm. 07-03, en línea: $<$ http://richmondfed.org/publications/economic_research/working_papers/index.cfm $>$, consultado el 8 de agosto de 2011.

Morvant-Roux, Solène, 2009, “L' anthropo-économie: un detour indispensable pour comprendre l'appropriation de la microfinance", en Revue Tiers-Monde, núm. 197, pp. 109-130.

Organización para la Cooperación y el Desarrollo Económicos (OCDE), 2005, Improving Financial Literacy:
Analysis of Issues and Policies, Organización para la Cooperación y el Desarrollo Económicos, París.

Porter, Katherine M. y Deborah Thorne, 2006, “The Failure of Bankruptcy's Fresh Start”, en Cornell Law Review, núm. 92, pp. 67-128.

Roesch, Marc y Ophelie Heliès, 2007, "La microfinance: outil de gestion du risque ou de mise en danger par sur-endettement?", en Revue Autrepart, núm. 44, pp. 119-140.

Servet, Jean-Michel, 2006, Banquiers aux pieds nus, Odile Jacob, París.

Shipton, Parker, 2007, The Nature of Entrustment. Intimacy, Exchange and the Sacred in Africa, Yale University Press, New Haven.

Villarreal, Magdalena, 2004, "Striving to Make Capital do 'Economic Things' for the Impoverished: On the Issue of Capitalization in Rural Microenterprises”, en Tiina Kontinen (ed.), Development Intervention: Actor and Activity Perspectives, Center for Activity Theory and Developmental Work Research, Institute for Development Studies, Universidad de Helsinki, Helsinki, pp. 67-81.

, 2009, Mujeres, finanzas sociales y violencia económica en zonas marginadas de Guadalajara, Instituto Jalisciense de las Mujeres, Instituto Municipal de las Mujeres en Guadalajara, Guadalajara.

Wampfler, Betty, Emmanuelle Bouquet y Eliane Ralison, 2013, "Does Juggling Mean Struggling? Insights into the Financial Practices of Rural Households in Madagascar”, en Isabelle Guérin, Solène Morvant-Roux y Magdalena Villarreal (eds.), Microfinance, Indebtedness and Over-indebtedness: Juggling with Money, Taylor and Francis, Hudson.

Weber, Florence, 2000, “Transactions marchandes, échanges rituels, relations personnelles. Une ethnographie économique après le Grand Partage”, en Genèses, núm. 41, pp. 85-107.

Yunus, Muhammad, 2007, Creating a World without Poverty: Social Business and the Future of Capitalism, New Africa Press, Pretoria.

Zelizer, Viviana, 2005, The Purchase of Intimacy, Princeton University Press, Princeton. 